\title{
EDITORIAL
}

\section{En memoria de nuestro entrañable amigo, Dr. Leopoldo Chiappo Galli}

El Dr. Chiappo era Vicerrector de la Universidad Peruana Cayetano Heredia, cuando la presidía el Dr. Alberto Hurtado Abadía. Por entonces, los gestores de la Facultad de Estomatología nos encontrábamos en el momento de presentar su proyecto de creación. Eran los primeros meses de 1969.

Los amigos de la Dirección de Planificación de la Universidad, donde se preparaba el proyecto, Ingeniero Hugo Pereyra Plasencia que la presidía y el Dr. Ramiro Castro de la Mata, me aconsejaron que visitara al Dr. Chiappo para exponerle las ideas fundamentales que sostenían el proyecto de creación de la nueva facultad. Con ese propósito solicité una entrevista con el Vicerrector, quien me recibió prontamente en su oficina, ubicada temporalmente en uno de los ambientes del Hospital Cayetano Heredia, a punto de ser inaugurado.

En el Dr. Chiappo encontré la más cordial acogida desde el primer apretón de manos. Le expuse las razones que nos llevaban a plantear la creación de una facultad que formara cirujanos dentistas y auxiliares de odontología. La salud bucal de la población, particularmente la de menos recursos, se deterioraba cada día más y la educación odontológica requería un fuerte impulso para superar largos años de retraso si se la comparaba con la de otros países del continente. A estas consideraciones de fondo, se sumaba la expresa dedicación de la Universidad Peruana Cayetano Heredia a la educación de profesionales en el campo de la salud. La creación de la nueva facultad no haría sino ayudar a completar el equipo de salud. Había otro factor favorable, los cursos de formación básica podrían ser impartidos por la misma Facultad de Ciencias, cuyos profesores e instalaciones se encontraban en un excelente momento de desarrollo.

Luego de escuchar atentamente nuestra presentación el Dr. Chiappo se declaró coincidente con las razones expuestas, asegurando su total apoyo al proyecto de creación de la nueva facultad. Recuerdo con nitidez las expresiones de entusiasmo en el rostro del Dr. Chiappo, un académico que amaba entrañablemente a su institución, pues fue uno de sus gestores; no solo ofreció su colaboración si no que, imaginativo y generoso como era, nos ofreció en ese mismo momento ideas enriquecedoras para el proyecto.

Más adelante, la comisión organizadora de la nueva facultad invitó al Dr. Chiappo a una de sus sesiones semanales en mi domicilio del distrito de Pueblo Libre. Ese día recibimos al Dr. Chiappo a eso de las ocho de la noche y lo tuvimos de amenísimo contertulio hasta pasada las doce. Hubo oportunidad para escuchar, de boca de uno de los fundadores de la Universidad, hechos de su historia matizados con graciosas anécdotas que contribuyeron a crear un clima de camaradería y amistad más allá de los rigores académicos. Del resultado de este encuentro se reforzaron los lazos afectivos que nos extendiera la noble personalidad del Dr. Chiappo, a quien comenzamos a llamar por su nombre. Ahora era el amigo Leopoldo quien apoyó la creación de la Facultad de Estomatología y siguió de cerca su desarrollo en el transcurrir de los años. A los dentistas nos decía Arquitectos de la Sonrisa, apelativo que alguno de nosotros solía completar... e ingenieros de puentes y coronas. Leopoldo celebró con nosotros el exitoso desarrollo de la facultad.

Con estas líneas de sincero aprecio, la Facultad de Estomatología desea expresar a los familiares del Dr. Chiappo y a la Comunidad Herediana, lo mucho que lo extrañamos y lo inolvidable que será para nosotros su cordial amistad.

Dr. Roberto J. Beltrán.

Profesor Emérito 